\title{
Use of PERCIST for Prediction of Progression-Free and Overall Survival After Radioembolization for Liver Metastases from Pancreatic Cancer
}

\author{
Marlies Michl ${ }^{1}$, Sebastian Lehner ${ }^{2}$, Philipp M. Paprottka ${ }^{3}$, Harun Ilhan², Peter Bartenstein ${ }^{2,4}$, Volker Heinemann ${ }^{1,4}$, \\ Stefan Boeck ${ }^{1,4}$, Nathalie L. Albert ${ }^{2}$, and Wolfgang P. Fendler ${ }^{2}$ \\ ${ }^{1}$ Department of Hematology and Oncology, Ludwig-Maximilians-University of Munich, Munich, Germany; ${ }^{2}$ Department of Nuclear \\ Medicine, Ludwig-Maximilians-University of Munich, Munich, Germany; ${ }^{3}$ Department of Clinical Radiology, Ludwig-Maximilians- \\ University of Munich, Munich, Germany; and ${ }^{4}$ Comprehensive Cancer Center Munich (CCCM), Ludwig-Maximilians-University of \\ Munich, Munich, Germany
}

\begin{abstract}
We evaluated the prognostic accuracy of established PET response criteria in patients with liver metastases from pancreatic cancer after treatment with ${ }^{90} \mathrm{Y}$ microspheres. Methods: Seventeen patients underwent ${ }^{18} \mathrm{~F}$-FDG PET/CT before and $3 \mathrm{mo}$ after radioembolization for liver metastases from pancreatic cancer. Overall survival, progression-free survival, and time to intrahepatic progression were among other factors correlated with metabolic response as revealed

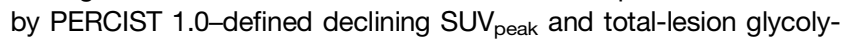
sis. Results: Metabolic response by change in $\operatorname{SUV}_{\text {peak }}(7 / 17)$ and change in total-lesion glycolysis $(7 / 17)$ was a predictor for overall survival $(P=0.039$; hazard ratio $[\mathrm{HR}], 0.24$; 95\% confidence interval $[\mathrm{Cl}], 0.06-0.93)$, progression-free survival $(P=0.016$; HR, 0.15; 95\% $\mathrm{Cl}, 0.03-0.69)$, and time to intrahepatic progression $(P=0.010$; HR, $0.16 ; 95 \% \mathrm{Cl}, 0.04-0.65)$. A summed baseline CT diameter of less than $8 \mathrm{~cm}$ for the 2 largest liver metastases predicted time to intrahepatic progression $(P=0.013$; HR, 0.21 ; $95 \% \mathrm{Cl}, 0.06-0.72)$ but did not predict overall or progression-free survival. Patient outcome was not predicted by other parameters, including baseline SUV peak, baseline total-lesion glycolysis, or change in serum level of carcinoembryonic antigen or carbohydrate antigen 19-9 from baseline to followup (each, $P>0.05$ ). Conclusion: Metabolic response by ${ }^{18} \mathrm{~F}-\mathrm{FDG}$ PET/CT predicts overall survival, progression-free survival, and time to intrahepatic progression after radioembolization for liver metastases from pancreatic cancer.
\end{abstract}

Key Words: survival; pancreatic cancer; PET; FDG; radioembolization; PERCIST; response

J Nucl Med 2016; 57:355-360

DOI: 10.2967/jnumed.115.165613

$\mathbf{P}$ ancreatic cancer remains one of the most aggressive types of solid tumors, notorious for rapidly leading to death once metastasized (1). Despite the advent of new chemotherapeutic regimens such as FOLFIRINOX (oxaliplatin, irinotecan, and fluorouracil) or gemcitabine/nab-paclitaxel for metastatic disease, median progression-

\footnotetext{
Received Aug. 17, 2015; revision accepted Oct. 28, 2015.

For correspondence or reprints contact: Wolfgang P. Fendler, Department

of Nuclear Medicine, Marchioninistrasse 15, 81377 Munich, Germany.

E-mail: wolfgang.fendler@med.uni-muenchen.de

Published online Nov. 25, 2015.

COPYRIGHT (c) 2016 by the Society of Nuclear Medicine and Molecular Imaging, Inc.
}

free survival (PFS) remains less than $6 \mathrm{mo}$, and overall survival (OS) is still less than a year $(2,3)$. Liver represents the dominant metastatic site of pancreatic cancer; radioembolization using ${ }^{90} \mathrm{Y}$ microspheres has emerged as a new treatment option in patients with unresectable liver disease, although experience with this approach is quite limited to date (4). In our recent analysis of radioembolization in 19 patients with liver metastases from pancreatic cancer, we reported encouraging local response rates and manageable toxicities (5). However, the patients in this preliminary study had shown considerable variation in PFS after radioembolization, which ranged from only 1 mo to more than $1 \mathrm{y}$, indicating a need for prediction of treatment response. Given the manifold options for local or systemic treatment of metastatic pancreatic cancer, it is crucial to identify those patients at high risk for tumor progression in order to optimally adapt their consequent treatment. In several studies of liver metastases from sources other than the pancreas, changes in tumor glycolytic rate by PET with the glucose analog ${ }^{18} \mathrm{~F}$-FDG proved to be predictive of response to radioembolization (6-10). Indeed, ${ }^{18} \mathrm{~F}-\mathrm{FDG}$ PET provided accuracy superior to CT in monitoring response and predicting survival in various solid tumors $(11,12)$. In particular, quantitation of ${ }^{18}$ F-FDG uptake using SUV has become routine for determining tumor response to therapy. Thus, a high pretreatment $\mathrm{SUV}_{\text {max }}$ has been associated with a short PFS, and a decrease in SUV $_{\text {max }}$ between baseline and follow-up was a predictor for PFS and OS after concurrent chemoradiotherapy in patients with locally advanced and metastatic pancreatic cancer $(13,14)$.

The present study aimed to investigate in more detail the role of SUV-based parameters derived from ${ }^{18} \mathrm{~F}-\mathrm{FDG}$ PET with regard to prediction of response and survival after radioembolization in patients with liver metastases from pancreatic cancer. Evaluations were performed according to PERCIST 1.0 (15). We hypothesized that a significant decrease in glucose metabolism after radioembolization is associated with longer survival.

\section{MATERIALS AND METHODS}

\section{Patients}

Between May 2004 and January 2015, 17 consecutive patients underwent radioembolization for liver metastases from pancreatic cancer with baseline and follow-up ${ }^{18} \mathrm{~F}-\mathrm{FDG}$ PET/CT in the Department of Nuclear Medicine of Ludwig-Maximilians-University Munich. The inclusion criteria for radioembolization were similar to those reported 
in our previous studies $(8,16)$ : an age of at least $18 \mathrm{y}$; unresectable, progressive liver metastases from pancreatic cancer refractory to systemic therapy; no evidence of a second malignancy of a different origin at the time of radioembolization; preserved liver function (defined by serum total bilirubin $\leq 2.0 \mathrm{mg} / \mathrm{dL}$ ); a Karnofsky index of at least $60 \%$ (17); an estimated preradioembolization life expectancy of at least $3 \mathrm{mo}$; and fitness to undergo preradioembolization examinations (angiography, scintigraphy, and ${ }^{18} \mathrm{~F}-\mathrm{FDG}$ PET/CT). Patients with limited extrahepatic metastases were admitted to radioembolization if the hepatic metastases were deemed to be predominant and presumably life-limiting. Exclusion criteria were liver failure (defined by bilirubin $>2.0 \mathrm{mg} / \mathrm{dL}$ or by the presence of ascites); uncorrectable blood flow from the hepatic artery to gastrointestinal organs, as observed on preradioembolization examinations; a pulmonary shunt of more than $20 \%$, as measured with preradioembolization ${ }^{99 \mathrm{~m} T c-l a b e l e d}$ macroaggregated albumin scintigraphy; or complete portal venous occlusion $(18,19)$. Thirteen of the 17 patients were included in our previous study on the efficacy and safety of radioembolization in liver metastases from pancreatic cancer (5). All patients gave written consent to undergo radioembolization. The ethical committee of LudwigMaximilians-University Munich approved this retrospective study, and the requirement to obtain informed consent for inclusion in the present analysis was waived.

\section{Radioembolization}

SIR-Spheres (Sirtex Medical) are resin microspheres containing ${ }^{90} \mathrm{Y}$, a $\beta$-emitting radionuclide with a 64.2 -h half-life. Thirteen patients received radioembolization of the whole-liver in a single session, and 4 patients were treated with lobar radioembolization in 2 separate sessions 4 wk apart. Microspheres were applied directly into the right and left hepatic arteries. The administered ${ }^{90} \mathrm{Y}$ activity was calculated in 14 patients on the basis of percentage involvement of liver volume and body surface area as follows:

$$
\begin{aligned}
\text { Activity }= & (\text { body surface area }-0.2) \\
& +(\text { liver involvement }(\%) / 100) .
\end{aligned}
$$

In the first 3 cases, activity was determined by an empiric algorithm: $2.0 \mathrm{GBq}$ for less than $25 \%$ involvement of the liver or $2.5 \mathrm{GBq}$ for more than $25 \%$ involvement.

\section{PET/CT Imaging}

Whole-body ${ }^{18} \mathrm{~F}-\mathrm{FDG}$ PET/CT images were acquired using a Biograph 64 TruePoint PET/CT scanner $(n=28$ [82\%]; Siemens Medical Solutions) or a Gemini scanner ( $n=6$ [18\%]; Philips). In none of the patients were the baseline and follow-up examinations performed on different PET instruments. The patients fasted at least $6 \mathrm{~h}$ to achieve a blood glucose level of no more than 150 $\mathrm{mg} / \mathrm{dL}$ at the time of ${ }^{18} \mathrm{~F}-\mathrm{FDG}$ injection. Emission scans were initiated $60 \mathrm{~min}$ after almost simultaneous intravenous administration of $20 \mathrm{mg}$ of furosemide, $10 \mathrm{mg}$ of butylscopolamine, and 300 $\mathrm{MBq}$ of ${ }^{18} \mathrm{~F}-\mathrm{FDG}$. Diagnostic CT scans of the neck, thorax, abdomen, and pelvis (100-190 mAs, depending on the scanned organ region; $120 \mathrm{kV}$ ) were acquired after intravenous injection of an iodine-containing contrast agent (Ultravist 300 [Schering] or Imeron 300 [Bracco], $2.5 \mathrm{~mL} / \mathrm{s}$ ) at a dose adjusted to body weight. Initiation of the CT acquisition was delayed $50 \mathrm{~s}$ after injection of the contrast agent to depict the portal venous phase. Studies based on standard phantom NU 2-2001 of the National Electrical Manufacturers Association were conducted on the two instruments, and SUV conversion factors were calculated to allow valid pooling of the results $(7,20)$.

\section{Response Assessment}

All patients underwent ${ }^{18} \mathrm{~F}-\mathrm{FDG}$ PET/CT and tumor marker testing before and 3 mo after radioembolization. Metabolic response was determined separately for changes in $\mathrm{SUV}_{\text {peak }}$ or total-lesion glycolysis (TLG) in accordance with PERCIST (15). In a slight modification of the PERCIST standard, we adjusted SUV $\left(\mathrm{g} / \mathrm{cm}^{3}\right)$ to body weight rather than to body surface area. This difference is unlikely to present a significant confounder because percentage SUV difference from baseline to followup was the primary readout for treatment response. TLG was calculated as grams. $\mathrm{SUV}_{\text {peak }}$ was measured in the single liver lesion with the highest uptake on baseline and follow-up PET. In view of the high average tumor burden of the liver, up to 5 liver lesions with the highest uptake were identified for TLG measurement at baseline and follow-up PET. Metabolic tumor volume was delineated on the basis of an SUV exceeding the mean SUV of healthy liver by at least 3 SDs. This approach is in accordance with PERCIST as defined on page 143S of a review by Wahl et al. (15). Mean healthy-liver SUV was defined as $\mathrm{SUV}_{\text {mean }}$ in a $15 \mathrm{~cm}^{3}$ spheric volume of interest positioned in a nondiseased area of the right hepatic lobe. The sum of the product $\left(\mathrm{SUV}_{\text {mean }} \times\right.$ metabolic tumor volume) from each of the 5 lesions was calculated as $\mathrm{TLG}_{5}$. Progressive disease (PD) was defined as an increase in either baseline PET parameter by more than $30 \%$ between baseline and follow-up or by the appearance of a new ${ }^{18} \mathrm{~F}$ FDG-avid lesion. Partial response (PR) was defined as any decrease of more than $30 \%$ in either baseline PET parameter. Complete response (CR) was defined as complete resolution of abnormal ${ }^{18} \mathrm{~F}$-FDG uptake within measurable target lesions, such that uptake equaled or fell below mean healthy-liver activity on the follow-up examination. Stable disease was defined as non-PD, non-PR, and non-CR. The summation of the largest diameters of the 2 largest lesions $\left(\mathrm{LD}_{2}\right.$, in $\left.\mathrm{cm}\right)$ was measured on the baseline CT image in accordance with RECIST 1.1 (21). PET/CT measurements using image fusion software (Hybrid Viewer; Hermes Medical Solutions) were performed by one interpreter with more than $5 \mathrm{y}$ of experience in clinical and scientific interpretation of ${ }^{18} \mathrm{~F}-\mathrm{FDG}$ PET/CT scans for tumor staging. Any decrease in carbohydrate antigen 19-9 (CA19-9) or carcinoembryonic antigen (CEA) serum level between baseline and follow-up was taken as a tumor marker response.

\section{Outcome Assessment}

The primary endpoint was OS, which was defined as the interval between the date of radioembolization and the last date of contact (as censored observation) or the date of disease-related death (as the event of interest). Secondary endpoints were PFS as defined by the U.S. Food and Drug Administration (22) and time to intrahepatic progression (TTP), which was defined as the time from radioembolization to objective progression of liver disease. Follow-up examinations were performed every 3 mo or at shorter intervals as clinically indicated. Objective progression was defined as PD according to RECIST 1.1 on follow-up CT or MRI (21). The observation period ended July 1, 2015.

\section{Statistical Analysis}

All data were analyzed retrospectively. Quantitative data are presented as number or median. The optimal cutoff for baseline tumor size $\left(\mathrm{LD}_{2}\right)$, $\mathrm{SUV}_{\text {peak }}$, and $\mathrm{TLG}_{5}$ was defined as the point on the receiver-operatingcharacteristic curve that was farthest from the line of equality (Youden index). Kaplan-Meier analysis of survival was based on the interval between the start of radioembolization and the last date of contact or the event of interest. Quantitative survival data are given as median and interquartile range (IQR), in months. A log rank test was used for statistical comparison of survival rates between independent subgroups. Univariate survival analysis was performed using Cox proportional hazards regression. Corresponding estimates for hazard ratio (HR) and 95\% confidence interval (CI) were calculated. Significance was set at a $P$ value of less than 0.05 for rejection of the null hypothesis. The SPSS software package (version 15.0; IBM) was used for all statistical analyses. 
TABLE 1

Characteristics of Study Cohort at Baseline $(n=17)$

\begin{tabular}{|c|c|}
\hline Characteristic & Data \\
\hline Age $(y)$ & $64.0($ IQR, 13.0) \\
\hline \multicolumn{2}{|l|}{ Sex } \\
\hline Male & $9(53 \%)$ \\
\hline Female & $8(47 \%)$ \\
\hline \multicolumn{2}{|l|}{ Primary tumor site } \\
\hline Head and papilla & $10(59 \%)$ \\
\hline Body and tail & $7(41 \%)$ \\
\hline \multicolumn{2}{|c|}{ Tumor sites at time of radioembolization } \\
\hline Liver only & $9(53 \%)$ \\
\hline Extrahepatic disease & $8(47 \%)$ \\
\hline Hepatic tumor burden (\%) & $20.0($ IQR, 12.5) \\
\hline Radioactivity delivered (GBq) & $1.7(\mathrm{IQR}, 0.5)$ \\
\hline \multicolumn{2}{|l|}{ Pretreatment } \\
\hline \multicolumn{2}{|l|}{ Surgery } \\
\hline Whipple & $8(47 \%)$ \\
\hline Left-sided pancreatic resection & $3(18 \%)$ \\
\hline Partial liver resection & $1(6 \%)$ \\
\hline \multicolumn{2}{|l|}{ Radiation therapy targeting } \\
\hline Pancreas & $2(12 \%)$ \\
\hline Liver & $1(6 \%)$ \\
\hline \multicolumn{2}{|l|}{ Palliative chemotherapy } \\
\hline Gemcitabine & $12(71 \%)$ \\
\hline Gemcitabine and erlotinib & $4(24 \%)$ \\
\hline Other & $1(6 \%)$ \\
\hline \multicolumn{2}{|l|}{ PET/CT parameters } \\
\hline $\mathrm{LD}_{2}(\mathrm{~cm})$ & $7.2(\mathrm{IQR}, 7.2)$ \\
\hline $\mathrm{TLG}_{5}(\mathrm{~g})$ & $156.0(\mathrm{IQR}, 394.2)$ \\
\hline $\operatorname{SUV}_{\text {peak }}\left(\mathrm{g} / \mathrm{cm}^{3}\right)$ & $9.4(\mathrm{IQR}, 5.2)$ \\
\hline
\end{tabular}

Data are total number followed by percentage, or median followed by IQR.

\section{RESULTS}

\section{Characteristics of Study Cohort and Survival}

Patient characteristics are presented in Table 1. Eight patients (47\%) presented with extrahepatic metastases. Before radioembolization, palliative chemotherapy with gemcitabine was given to 12 patients $(71 \%)$, four of whom received it in combination with erlotinib; 11 patients had pancreatic surgery; and 1 patient each had partial liver resection or radiation therapy targeting the liver. The median OS, PFS, and TTP were $8.8 \mathrm{mo}$ (IQR, 7.2 mo), $2.9 \mathrm{mo}$ (IQR, $3.3 \mathrm{mo}$ ), and $3.5 \mathrm{mo}$ (IQR, $5.8 \mathrm{mo}$ ), respectively, for the entire cohort. Two patients were still alive and 4 patients had no liver progression at the end of the observation period. There was no censored event for PFS.

\section{PERCIST Response and Baseline Parameters}

Median tumoral SUV $\mathrm{Seak}_{\text {was }}$ 9.4 (IQR, 5.2) (range, 2.2-27.6) at baseline and 4.2 (IQR, 3.4) (range, 2.6-23.2) at follow-up. Median change in $\mathrm{SUV}_{\text {peak }}$ between baseline and follow-up was $-47 \%$ (IQR, $75 \%$ ) (range, $-86 \%-152 \%$ ). In 6 of 17 patients $(35 \%)$, the
$\mathrm{SUV}_{\text {peak }}$ increased from baseline to follow-up by a median of $117 \%$ (IQR, 92\%) (range, 3\%-152\%). Median tumoral TLG 5 was 156.0 (IQR, 394.2) (range, 1.0-1,795.0) at baseline and 54.0 (IQR, 400.0) (range, 0.0-6,482.0) at follow-up. Median change in $\mathrm{TLG}_{5}$ between baseline and follow-up was $-90 \%$ (IQR, 259\%) (range, $-100 \%-$ $39,900 \%$ ). Independent analysis of PET parameters resulted in the same response category for each patient: 6 of 17 patients $(35 \%)$ had $\mathrm{CR}$, one patient (6\%) had PR, and 10 patients (59\%) had PD accord-

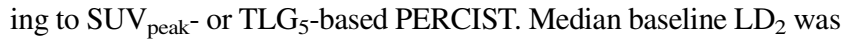
$7.2 \mathrm{~cm}$ (IQR, $7.2 \mathrm{~cm}$ ).

\section{Survival Analysis}

Receiver-operating-characteristic analysis resulted in optimal cutoffs of $7.9 \mathrm{~cm}$ for baseline $\mathrm{LD}_{2}, 5.1$ for baseline $\mathrm{SUV}_{\text {peak }}$, and 55 for baseline $\mathrm{TLG}_{5}$. The results for univariate analysis of changes in $\mathrm{SUV}_{\text {peak }}, \mathrm{TLG}_{5}, \mathrm{CEA}, \mathrm{CA1}$ 19-9, and baseline parameters are presented in Table 2 for OS and Table 3 for PFS and TTP. Figure 1 shows the corresponding Kaplan-Maier survival curves.

Response by changes in either $\mathrm{SUV}_{\text {peak }}$ or TLG $\mathrm{TL}_{5}$ based on PERCIST was significantly associated with favorable OS, PFS, and TTP. Patients with any response (PR or CR) according to PERCIST $(n=7)$ had a 4.2-fold decreased risk of death $(P=0.039$; HR, 0.24; 95\% CI, 0.06$0.93)$, a 6.7-fold decreased risk of overall progression $(P=0.016$; HR, 0.15 ; 95\% CI, 0.03-0.69), and a 6.3-fold decreased risk of liver progression $(P=0.010 ; \mathrm{HR}, 0.16 ; 95 \% \mathrm{CI}, 0.04-0.65)$. Outcome in patients with $\mathrm{PR}$ or $\mathrm{CR}(n=7)$ versus $\mathrm{PD}(n=10)$ according to PERCIST was $14.6 \mathrm{mo}$ (IQR, $20.9 \mathrm{mo}$ ) versus $5.2 \mathrm{mo}$ (IQR, $5.6 \mathrm{mo}$ ) for OS, $5.9 \mathrm{mo}$ (IQR, $4.7 \mathrm{mo}$ ) versus $2.8 \mathrm{mo}$ (IQR, $0.5 \mathrm{mo}$ ) for PFS, and $8.5 \mathrm{mo}$ (IQR, $12.7 \mathrm{mo}$ ) versus $2.8 \mathrm{mo}$ (IQR, $0.7 \mathrm{mo}$ ) for TTP. Figure 2 shows images from a representative patient with PR according to PERCIST, and Figure 3 shows the corresponding images from a patient with PD. A baseline $\mathrm{LD}_{2}$ of $7.9 \mathrm{~cm}$ or less was significantly associated with prolonged TTP. Figure 4 shows the corresponding Kaplan-Maier survival curves. Patients with an $\mathrm{LD}_{2}$ of $7.9 \mathrm{~cm}$ or less had a 4.8-fold decreased risk for liver progression $(P=0.013$; HR, 0.21 ; $95 \% \mathrm{CI}$, 0.06-0.72), whereas none of the other baseline PET/CT parameters were significant predictors of patient outcome (each, $P>0.05$ ).

In 7 of 17 patients (41\%), plasma CEA levels decreased by a median of $64 \%$ (IQR, 27\%) (range, -98 to $-8 \%$ ) between baseline

TABLE 2

Regression Analysis for OS

\begin{tabular}{|c|c|c|c|c|c|}
\hline \multirow[b]{2}{*}{ Variable } & \multirow[b]{2}{*}{ Subcategory } & \multirow[b]{2}{*}{$n$} & \multicolumn{3}{|c|}{ OS } \\
\hline & & & $P$ & $\mathrm{HR}$ & $95 \% \mathrm{Cl}$ \\
\hline $\begin{array}{l}\text { Changes in } \\
\text { SUV }_{\text {peak }}\end{array}$ & CR or PR & 7 & $0.039^{\star}$ & 0.24 & $0.06-0.93$ \\
\hline $\begin{array}{l}\text { Changes in } \\
\text { TLG }_{5}\end{array}$ & CR or PR & 7 & $0.039^{*}$ & 0.24 & $0.06-0.93$ \\
\hline $\mathrm{LD}_{2}$ & $\leq 7.9 \mathrm{~cm}$ & 9 & 0.090 & 0.38 & $0.12-1.16$ \\
\hline$S U V_{\text {peak }}$ & $\leq 5.1$ & 3 & 0.209 & 0.38 & $0.08-1.73$ \\
\hline $\mathrm{TLG}_{5}$ & $\leq 55$ & 5 & 0.559 & 1.41 & $0.44-4.51$ \\
\hline $\begin{array}{l}\text { Changes in } \\
\text { CEA }\end{array}$ & Any decrease & 7 & 0.138 & 0.40 & $0.12-1.34$ \\
\hline $\begin{array}{c}\text { Changes in } \\
\text { CA19-9 }\end{array}$ & Any decrease & 10 & 0.691 & 0.81 & $0.28-2.34$ \\
\hline
\end{tabular}

${ }^{\star} P<0.05$ 
TABLE 3

Regression Analysis for PFS and TTP

\begin{tabular}{|c|c|c|c|c|c|c|c|c|}
\hline \multirow[b]{2}{*}{ Variable } & \multirow[b]{2}{*}{ Subcategory } & \multirow[b]{2}{*}{$n$} & \multicolumn{3}{|c|}{ PFS } & \multicolumn{3}{|c|}{ TTP } \\
\hline & & & $P$ & $\mathrm{HR}$ & $95 \% \mathrm{Cl}$ & $P$ & $\mathrm{HR}$ & $95 \% \mathrm{Cl}$ \\
\hline Changes in $S U V_{\text {peak }}$ & CR or PR & 7 & $0.016^{\star}$ & 0.15 & $0.03-0.69$ & $0.010^{*}$ & 0.16 & $0.04-0.65$ \\
\hline Changes in $\mathrm{TLG}_{5}$ & CR or PR & 7 & $0.016^{\star}$ & 0.15 & $0.03-0.69$ & $0.010^{*}$ & 0.16 & $0.04-0.65$ \\
\hline $\mathrm{LD}_{2}$ & $\leq 7.9 \mathrm{~cm}$ & 9 & 0.270 & 0.56 & $0.20-1.56$ & $0.013^{*}$ & 0.21 & $0.06-0.72$ \\
\hline$S_{\text {Suk }}$ & $\leq 5.1$ & 3 & 0.399 & 0.58 & $0.16-2.07$ & 0.678 & 0.72 & $0.16-3.33$ \\
\hline $\mathrm{TLG}_{5}$ & $\leq 55$ & 5 & 0.410 & 1.63 & $0.51-5.18$ & 0.507 & 0.64 & $0.17-2.38$ \\
\hline Changes in CEA & Any decrease & 7 & 0.131 & 0.42 & $0.14-1.30$ & 0.059 & 0.28 & $0.07-1.05$ \\
\hline Changes in CA19-9 & Any decrease & 10 & 0.967 & 0.98 & $0.35-2.73$ & 0.125 & 0.40 & $0.13-1.29$ \\
\hline${ }^{\star} P<0.05$ & & & & & & & & \\
\hline
\end{tabular}

and follow-up. In 10 of 17 patients (59\%), plasma CA19-9 levels decreased by a median of $46 \%$ (IQR, 55\%) (range, -99 to $-9 \%$ ) between baseline and follow-up. However, responses by changes in CEA or CA19-9 were not significantly associated with patient outcome.

\section{DISCUSSION}

The aim of the present study was to evaluate the value of several ${ }^{18}$ F-FDG PET parameters for prediction of survival in patients with liver metastases from pancreatic cancer receiving ${ }^{90} \mathrm{Y}$ microsphere radioembolization. For this purpose, we applied PERCIST to objectively assess treatment response based on changes in tumoral SUV $_{\text {peak }}$ or TLG (15).

The present analysis indicated that radioembolization has satisfactory efficacy for treatment of liver metastases from pancreatic cancer. Even though we applied radioembolization as a salvage treatment, median PFS was 2.9 mo and OS was $8.8 \mathrm{mo}$; the fact that these findings are similar to survival rates from large, prospective trials investigating first-line chemotherapy for hepatic metastasis $(2,3)$ implies a possible improvement in OS by radioembolization. The present results add to the small amount of literature on the significance of ${ }^{18}$ F-FDG PET/CT for staging and monitoring the treatment of pancreatic cancer. In an earlier report, ${ }^{18} \mathrm{~F}-\mathrm{FDG}$ PET/CT showed advantages over CT in the detection of distant metastasis in resectable and locally advanced stages of pancreatic cancer (23). Furthermore, pretreatment $\mathrm{SUV}_{\max }$ in metastatic pancreatic cancer has already been shown to be an independent predictor of PFS (13), and posttreatment changes in $\mathrm{SUV}_{\max }$ have been found
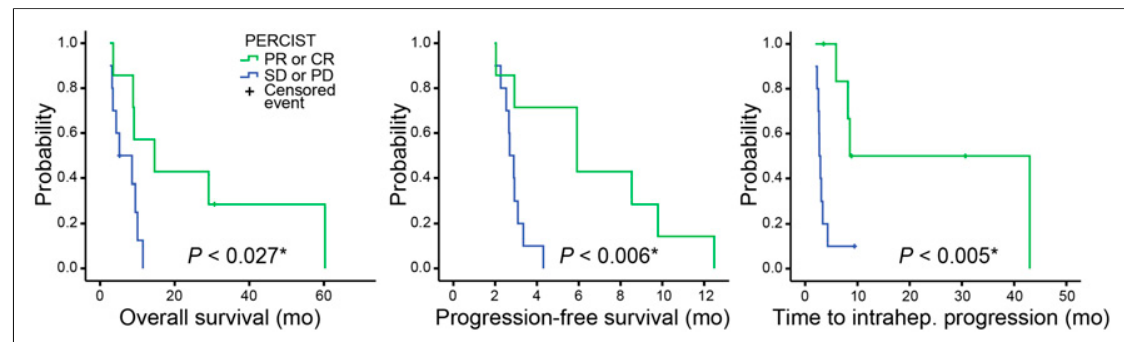

FIGURE 1. Kaplan-Meier survival curves for OS, PFS, and TTP in responders and nonresponders according to changes in $\mathrm{SUV}_{\text {peak }}$ or $\mathrm{TLG}_{5}$. ${ }^{*}$ Log rank test $P<0.05$. SD $=$ stable disease. to be significantly associated with outcome after concurrent chemoradiotherapy (14). On the basis of the criteria of the European Organization for Research and Treatment of Cancer (EORTC) PET Study Group, the SUV of the hottest tumor voxel $\left(\mathrm{SUV}_{\max }\right)$ has traditionally been considered a hallmark of tumor vitality, useful for predicting metabolic response to treatment (24). Indeed, several studies have reported that $\mathrm{SUV}_{\max }$ is more accurate than tumor size for prediction of outcome after radioembolization for unresectable liver metastases of different origins $(6,7,25)$. However, a consensus group developed PERCIST to overcome certain limitations of the EORTC criteria and thus to serve as an improved framework for ${ }^{18} \mathrm{~F}-\mathrm{FDG}$ PET response assessment (15). PERCIST defines $S_{U V}$ peak as the primary surrogate for tumor vitality, this index being less susceptible than $\mathrm{SUV}_{\max }$ to noise, especially in modern, high-resolution PET scanners (26). The consensus includes TLG of a predefined tumor volume as a secondary readout for tumor vitality. However, to our knowledge, before this report the prognostic value of metabolic response by PERCIST after local treatment of liver metastases from pancreatic or other origin had not been investigated. We found in our 17 patients that the median $\mathrm{SUV}_{\text {peak }}$ of the single liver lesion with the highest ${ }^{18} \mathrm{~F}$-FDG uptake decreased from 9.4 at baseline to 4.2 at follow-up after radioembolization. The median summed tumoral $\mathrm{TLG}_{5}$ dropped from 156 at baseline to 54 at follow-up. Six of 17 patients (35\%) had CR, one patient had PR, and 10 patients (59\%) had PD according to $\mathrm{SUV}_{\text {peak }}{ }^{-}$or $\mathrm{TLG}_{5}$-based PERCIST. As hypothesized, PERCIST responders had a significantly longer OS (HR, 0.24; $P=0.039)$, PFS (HR, 0.15; $P=0.016$ ), and TTP (HR, 0.16; $P=0.010)$ than nonresponders did (Fig. 1; Tables 2 and 3). These results are consistent with recently published findings on colorectal cancer, hepatocellular carcinoma, cholangiocellular carcinoma, and breast cancer $(6-8,27,28)$ showing that changes in SUV or TLG between baseline and follow-up are generally predictive of OS after radioembolization. The fact that the present independent analysis of changes in $\mathrm{SUV}_{\text {peak }}$ and $\mathrm{TLG}_{5}$ assigned the same response category for each of our 17 patients further underlines the consistency of the definition of response as established in PERCIST (15). 

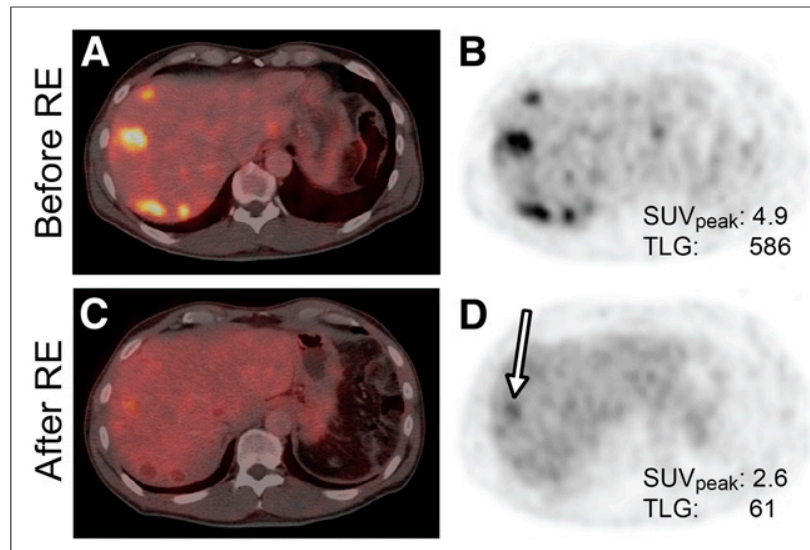

FIGURE 2. A 60-y-old man with partial metabolic response. Axial ${ }^{18} \mathrm{~F}-$ FDG PET/CT (A and C) and PET (B and D) images before and 3 mo after radioembolization are shown. $\mathrm{SUV}_{\text {peak }}$ was 4.9 at baseline and 2.6 at follow-up (-47\%; PR according to PERCIST). Residual uptake was recorded in one lesion (arrow) on follow-up. TLG ${ }_{5}$ was 586 at baseline and 61 at follow-up (-90\%; PR according to PERCIST). Patient had OS of $30.7 \mathrm{mo}$, PFS of $9.8 \mathrm{mo}$, and TTP of $30.7 \mathrm{mo}$, as compared with respective medians of $8.8,2.9$, and 3.5 mo for entire cohort. $\mathrm{RE}=$ radioembolization.

Pretreatment PET/CT parameters including $\mathrm{LD}_{2}, \mathrm{SUV}_{\text {peak }}$, and $\mathrm{TLG}_{5}$ also correlated with treatment response in the liver (TTP) and with survival. In accordance with RECIST 1.1, we calculated $\mathrm{LD}_{2}$ on baseline CT (21). A baseline $\mathrm{LD}_{2}$ of $7.9 \mathrm{~cm}$ or less proved to be significantly associated with prolonged TTP, although we saw no such correlation with PFS or OS (Fig. 4). Our findings demonstrate that small liver metastases are associated with a better treatment response than large ones, implying that radioembolization may be more effective when applied earlier in the course of
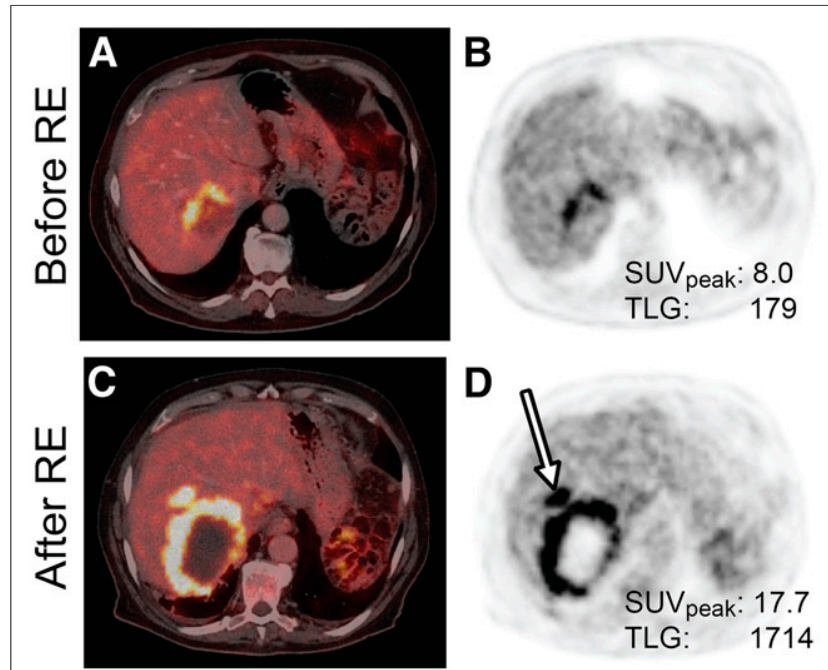

FIGURE 3. A 77-y-old man with progressive metabolic disease. Axial ${ }^{18} \mathrm{~F}-\mathrm{FDG}$ PET/CT (A and C) and PET (B and D) images before and 3 mo after radioembolization are shown. SUV peak $_{\text {was }} 8.0$ at baseline and 17.7 at follow-up (+121\%). New liver lesions were seen on follow-up

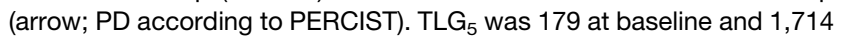
at follow-up (+858\%; PD according to PERCIST). Patient had OS of $5.2 \mathrm{mo}$, PFS of $2.9 \mathrm{mo}$, and TTP of $2.9 \mathrm{mo}$, as compared with respective medians of $8.8,2.9$, and 3.5 mo for entire cohort.

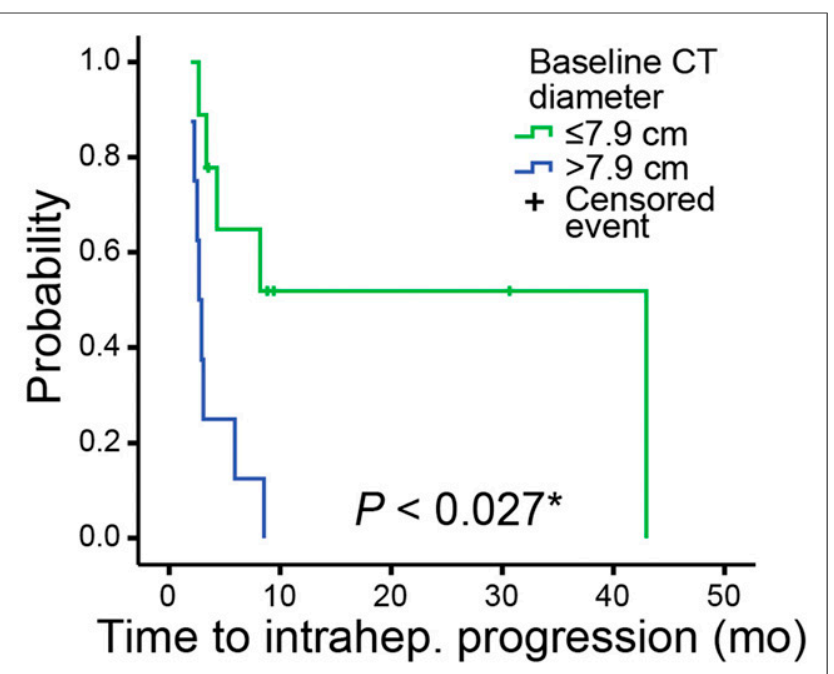

FIGURE 4. Kaplan-Meier survival curves for TTP in patients with baseline $\mathrm{LD}_{2} \leq 7.9 \mathrm{~cm}$ vs. $>7.9 \mathrm{~cm}$. ${ }^{\star}$ Log rank test $P<0.05$.

disease. Surprisingly, we saw no correlation between baseline $\mathrm{SUV}_{\text {peak }}$ or $\mathrm{TLG}_{5}$ and any endpoint (Tables 2 and 3). Although baseline $\mathrm{SUV}_{\text {max }}$ is presumed to be an indicator of tumor vitality and thus aggressiveness in many types of cancer $(29,30)$, and given that a high baseline $\mathrm{SUV}_{\max }$ has been described as an independent prognostic factor for progression of pancreatic cancer (13), we did not find baseline $\mathrm{SUV}_{\text {peak }}$ or $\mathrm{TLG}_{5}$ to be of value in predicting survival in our series of pancreatic cancer patients with liver metastases. Though the baseline level of CA19-9 demonstrated prognostic value in our previous study (5), response by CA19-9 and CEA failed to show a significant association with outcome in the present investigation. There is substantial evidence that baseline CA19-9 and CA19-9 kinetics can serve as useful surrogates for tumor progression in advanced and metastatic pancreatic cancer (31-33). The present discrepancy from the earlier literature may be due to the small number of patients included in our study or may reflect confounds arising from the treatment history of our patients.

The present study was limited by its retrospective single-center design in a small patient cohort with different metastatic patterns (Table 1). About half our patients presented with extrahepatic disease, which is known to be associated with short survival after radioembolization in patients with various types of cancer $(34,35)$. Indeed, the presence of extrahepatic metastases, which are not targeted by radioembolization, might have presented a strong confounder for OS in our patient cohort. Although these limitations confer a preliminary character to the present data, the patient and tumor characteristics were nevertheless representative of metastatic pancreatic cancer in the palliative setting, and adequate follow-up data were available for most patients.

\section{CONCLUSION}

Metabolic response by PERCIST predicts OS, PFS, and TTP after radioembolization for liver metastases from pancreatic cancer. Our findings underline the feasibility of ${ }^{18} \mathrm{~F}$-FDG PET/CT with PERCISTbased response prediction for local treatment of liver metastases from pancreatic cancer and may also generalize to liver metastases of nonpancreatic origin. 


\section{DISCLOSURE}

The costs of publication of this article were defrayed in part by the payment of page charges. Therefore, and solely to indicate this fact, this article is hereby marked "advertisement" in accordance with 18 USC section 1734. Marlies Michl, Philipp Paprottka, and Sebastian Lehner have received fees or travel-related expenses for events organized by Sirtex Medical (Sydney, Australia) outside the submitted work. Philipp Paprottka has an advisory relationship with Sirtex Medical outside the submitted work. No other potential conflict of interest relevant to this article was reported.

\section{ACKNOWLEDGMENT}

We thank Dr. Paul Cumming for revising the manuscript.

\section{REFERENCES}

1. SEER stat fact sheets: pancreas cancer. National Cancer Institute website. http:// seer.cancer.gov/statfacts/html/pancreas.html. Accessed December 22, 2015.

2. Conroy T, Desseigne F, Ychou M, et al. FOLFIRINOX versus gemcitabine for metastatic pancreatic cancer. N Engl J Med. 2011;364:1817-1825.

3. Von Hoff DD, Ervin T, Arena FP, et al. Increased survival in pancreatic cancer with nab-paclitaxel plus gemcitabine. N Engl J Med. 2013;369:1691-1703.

4. Cao C, Yan TD, Morris DL, Bester L. Radioembolization with yttrium-90 microspheres for pancreatic cancer liver metastases: results from a pilot study. Tumori. 2010;96:955-958.

5. Michl M, Haug AR, Jakobs TF, et al. Radioembolization with yttrium-90 microspheres (SIRT) in pancreatic cancer patients with liver metastases: efficacy, safety and prognostic factors. Oncology. 2014;86:24-32.

6. Haug AR, Heinemann V, Bruns CJ, et al. ${ }^{18}$ F-FDG PET independently predicts survival in patients with cholangiocellular carcinoma treated with ${ }^{90} \mathrm{Y}$ microspheres. Eur J Nucl Med Mol Imaging. 2011;38:1037-1045.

7. Haug AR, Tiega Donfack BP, Trumm C, et al. ${ }^{18} \mathrm{~F}-\mathrm{FDG}$ PET/CT predicts survival after radioembolization of hepatic metastases from breast cancer. $\mathrm{J} \mathrm{Nucl}$ Med. 2012;53:371-377.

8. Fendler WP, Philippe Tiega DB, Ilhan H, et al. Validation of several SUVbased parameters derived from ${ }^{18} \mathrm{~F}$-FDG PET for prediction of survival after SIRT of hepatic metastases from colorectal cancer. J Nucl Med. 2013;54: 1202-1208.

9. Gulec SA, Suthar RR, Barot TC, Pennington K. The prognostic value of functional tumor volume and total lesion glycolysis in patients with colorectal cancer liver metastases undergoing ${ }^{90} \mathrm{Y}$ selective internal radiation therapy plus chemotherapy. Eur J Nucl Med Mol Imaging. 2011;38:1289-1295.

10. Soydal C, Kucuk ON, Gecim EI, Bilgic S, Elhan AH. The prognostic value of quantitative parameters of ${ }^{18} \mathrm{~F}-\mathrm{FDG}$ PET/CT in the evaluation of response to internal radiation therapy with yttrium-90 in patients with liver metastases of colorectal cancer. Nucl Med Commun. 2013;34:501-506.

11. Herrmann K, Benz MR, Czernin J, et al. ${ }^{18}$ F-FDG-PET/CT imaging as an early survival predictor in patients with primary high-grade soft tissue sarcomas undergoing neoadjuvant therapy. Clin Cancer Res. 2012;18:2024-2031.

12. Ott K, Weber WA, Lordick F, et al. Metabolic imaging predicts response, survival, and recurrence in adenocarcinomas of the esophagogastric junction. $J$ Clin Oncol. 2006;24:4692-4698.

13. Moon SY, Joo KR, So YR, et al. Predictive value of maximum standardized uptake value (SUVmax) on ${ }^{18} \mathrm{~F}$-FDG PET/CT in patients with locally advanced or metastatic pancreatic cancer. Clin Nucl Med. 2013;38:778-783.

14. Topkan E, Parlak C, Kotek A, Yapar AF, Pehlivan B. Predictive value of metabolic ${ }^{18}$ FDG-PET response on outcomes in patients with locally advanced pancreatic carcinoma treated with definitive concurrent chemoradiotherapy. BMC Gastroenterol. 2011;11:123.
15. Wahl RL, Jacene H, Kasamon Y, Lodge MA. From RECIST to PERCIST: evolving considerations for PET response criteria in solid tumors. J Nucl Med. 2009;50(suppl 1):122S-150S.

16. Fendler WP, Ilhan H, Paprottka PM, et al. Nomogram including pretherapeutic parameters for prediction of survival after SIRT of hepatic metastases from colorectal cancer. Eur Radiol. 2015;25:2693-26700.

17. Karnofsky DA, Burchenal JH. The clinical evaluation of chemotherapeutic agents in cancer. In: MacLeod CM, ed. Evaluation of Chemotherapeutic Agents. New York, NY: Columbia University Press; 1949:196.

18. Goin JE, Salem R, Carr BI, et al. Treatment of unresectable hepatocellular carcinoma with intrahepatic yttrium 90 microspheres: factors associated with liver toxicities. J Vasc Interv Radiol. 2005;16:205-213.

19. Ho S, Lau WY, Leung TW, Chan M, Johnson PJ, Li AK. Clinical evaluation of the partition model for estimating radiation doses from yttrium-90 microspheres in the treatment of hepatic cancer. Eur J Nucl Med. 1997;24:293-298.

20. NEMA NU 2: Performance Measurements of Positron Emission Tomographs. Rosslyn, VA: National Electrical Manufacturers Association; 2001:1-40.

21. Eisenhauer EA, Therasse P, Bogaerts J, et al. New response evaluation criteria in solid tumours: revised RECIST guideline (version 1.1). Eur J Cancer. 2009;45:228-247.

22. Guidance for Industry: Clinical Trial Endpoints for the Approval of Cancer Drugs and Biologics. Rockville, MD: U.S. Department of Health and Human Services; 2007:8.

23. Wang XY, Yang F, Jin C, Guan YH, Zhang HW, Fu DL. The value of ${ }^{18}$ F-FDG positron emission tomography/computed tomography on the pre-operative staging and the management of patients with pancreatic carcinoma. Hepatogastroenterology. 2014;61:2102-2109.

24. Young H, Baum R, Cremerius U, et al. Measurement of clinical and subclinical tumour response using $\left[{ }^{18} \mathrm{~F}\right]$-fluorodeoxyglucose and positron emission tomography: review and 1999 EORTC recommendations. European Organization for Research and Treatment of Cancer (EORTC) PET Study Group. Eur J Cancer. 1999;35:1773-1782.

25. Bienert M, McCook B, Carr BI, et al. ${ }^{90} \mathrm{Y}$ microsphere treatment of unresectable liver metastases: changes in ${ }^{18} \mathrm{~F}-\mathrm{FDG}$ uptake and tumour size on PET/CT. Eur J Nucl Med Mol Imaging. 2005;32:778-787.

26. Boellaard R, Krak NC, Hoekstra OS, Lammertsma AA. Effects of noise, image resolution, and ROI definition on the accuracy of standard uptake values: a simulation study. J Nucl Med. 2004;45:1519-1527.

27. Sabet A, Meyer C, Aouf A, et al. Early post-treatment FDG PET predicts survival after ${ }^{90} \mathrm{Y}$ microsphere radioembolization in liver-dominant metastatic colorectal cancer. Eur J Nucl Med Mol Imaging. 2015;42:370-376.

28. Sabet A, Ahmadzadehfar H, Bruhman J, et al. Survival in patients with hepatocellular carcinoma treated with ${ }^{90} \mathrm{Y}$-microsphere radioembolization. prediction by ${ }^{18}$ F-FDG PET. Nuklearmedizin. 2014;53:39-45.

29. Engelman ES, Leon-Ferre R, Naraev BG, et al. Comparison of transarterial liverdirected therapies for low-grade metastatic neuroendocrine tumors in a single institution. Pancreas. 2014;43:219-225.

30. Groheux D, Giacchetti S, Moretti JL, et al. Correlation of high ${ }^{18} \mathrm{~F}$-FDG uptake to clinical, pathological and biological prognostic factors in breast cancer. Eur $J$ Nucl Med Mol Imaging. 2011;38:426-435.

31. Haas M, Heinemann V, Kullmann F, et al. Prognostic value of CA 19-9, CEA, CRP, LDH and bilirubin levels in locally advanced and metastatic pancreatic cancer: results from a multicenter, pooled analysis of patients receiving palliative chemotherapy. J Cancer Res Clin Oncol. 2013;139:681-689.

32. Haas M, Laubender RP, Stieber P, et al. Prognostic relevance of CA 19-9, CEA, CRP, and LDH kinetics in patients treated with palliative second-line therapy for advanced pancreatic cancer. Tumour Biol. 2010;31:351-357.

33. Boeck S, Haas M, Laubender RP, et al. Application of a time-varying covariate model to the analysis of CA 19-9 as serum biomarker in patients with advanced pancreatic cancer. Clin Cancer Res. 2010;16:986-994.

34. Coldwell D, Sangro B, Salem R, Wasan H, Kennedy A. Radioembolization in the treatment of unresectable liver tumors: experience across a range of primary cancers. Am J Clin Oncol. 2012;35:167-177.

35. Kennedy AS, Ball D, Cohen SJ, et al. Multicenter evaluation of the safety and efficacy of radioembolization in patients with unresectable colorectal liver metastases selected as candidates for ${ }^{90} \mathrm{Y}$ resin microspheres. J Gastrointest Oncol. 2015;6:134-142. 